\title{
Influence of Morphine on Pharmacokinetics and Pharmacodynamics of Ticagrelor in Patients with Acute Myocardial Infarction (IMPRESSION): study protocol for a randomized controlled trial
}

\author{
Jacek Kubica ${ }^{1 \dagger}$, Piotr Adamski ${ }^{2^{*+}}$, Małgorzata Ostrowska², Marek Koziński ${ }^{2}$, Karolina Obońska ${ }^{1}$, Ewa Laskowska², \\ Ewa Obońska ${ }^{3}$, Grzegorz Grześk ${ }^{3}$, Piotr Winiarski ${ }^{4}$ and Przemysław Paciorek ${ }^{1}$
}

\begin{abstract}
Background: Ticagrelor is an oral platelet P2Y12 receptor antagonist which is recommended for patients suffering from myocardial infarction, both with and without persistent ST segment elevation. Morphine is the first choice drug in pain alleviation in the same clinical subset. Recently a possible negative influence of morphine on the pharmacokinetics and antiplatelet effects of P2Y12 receptor blockers has been postulated.

Methods/design: The IMPRESSION study is a phase IV, single center, randomized, double-blind, placebo-controlled clinical trial that is designed to assess the influence of morphine on the pharmacokinetics and pharmacodynamics of ticagrelor in patients with myocardial infarction. The study is planned to include up to 100 patients with myocardial infarction who will be randomized into one of two arms in a 1:1 ratio. Subjects in the intervention arm prior to the loading dose of ticagrelor (180 mg) will receive morphine $(5 \mathrm{mg})$ intravenously, whereas patients in the control arm will receive a placebo prior to the loading dose of ticagrelor $(180 \mathrm{mg})$. The pharmacokinetics of ticagrelor and its active metabolite (AR-C124910XX) will be assessed by liquid chromatography mass spectrometry. Platelet function testing in each patient will be performed using up to four different methods (platelet vasodilator-stimulated phosphoprotein assay, multiple electrode aggregometry, VerifyNow, and light transmission aggregometry).
\end{abstract}

Discussion: This study is expected to provide essential evidence-based data on the impact of morphine on the absorption of ticagrelor in patients with myocardial infarction as well as to shed some light on the suspected connection between morphine use and antiplatelet activity of ticagrelor in the same group of patients.

Trial registration: ClinicalTrials.gov identifier: NCT02217878 (14 August 2014).

Keywords: Ticagrelor, Morphine, Myocardial infarction, Pharmacokinetics, Pharmacodynamics

\section{Background}

Platelet activation and aggregation play a pivotal role in the pathophysiology of acute coronary syndromes (ACS), including ST-segment elevation myocardial infarction (STEMI) and non-ST-segment elevation myocardial infarction (NSTEMI). Dual antiplatelet therapy, consisting of aspirin and one of the P2Y12 receptor antagonists,

\footnotetext{
* Correspondence: piotr.adamski@wp.eu

${ }^{\dagger}$ Equal contributors

2Department of Principles of Clinical Medicine, Nicolaus Copernicus University, Collegium Medicum, 9 Skłodowskiej-Curie Street, 85-094 Bydgoszcz, Poland

Full list of author information is available at the end of the article
}

constitutes the mainstay of ACS treatment. Achievement of adequate and timely platelet inhibition is of vast importance in the acute phase of myocardial infarction. Results of the PLATO trial have shown that therapy with ticagrelor, a novel platelet P2Y12 receptor inhibitor, compared with clopidogrel reduces not only the rate of death from vascular causes, myocardial infarction, or stroke, but also all-cause mortality, without concomitant increase in the rate of overall major bleeding, in patients with ACS [1,2]. The superiority of ticagrelor over clopidogrel evidenced in the PLATO trial has been principally 


\section{Table 1 Inclusion and exclusion criteria for IMPRESSION study}

Inclusion Criteria

Provision of informed consent prior to any study-specific procedures

Diagnosis of acute STEMI or acute NSTEMI

Provision of informed consent for angiography and $\mathrm{PCl}$

Male or non-pregnant female, aged 18 to 80 years old

\section{Exclusion Criteria}

Chest pain described by the patient as unbearable or patient's request for analgesics

Prior morphine administration during the current STEMI or NSTEM

Treatment with ticlopidine, clopidogrel, prasugrel, or ticagrelor within 14 days before the study enrollment

Hypersensitivity to ticagrelor

Current treatment with oral anticoagulant or chronic therapy with LMWH

Active bleeding

History of intracranial hemorrhage

Recent gastrointestinal bleeding (within 30 days)

History of coagulation disorders

Concomitant therapy with strong CYP3A inducers (rifampicin, phenytoin, carbamazepine, dexamethasone, phenobarbital) within 14 days and during study treatment

Hemoglobin concentration less than $10.0 \mathrm{~g} / \mathrm{dl}$

History of moderate or severe hepatic impairment

LMWH: low-molecular-weight heparin; NSTEMI: non-ST-segment elevation myocardial infarction; NYHA: New York Heart Association; PCl: percutaneous coronary intervention; STEMI: ST-segment elevation myocardial infarction.

attributed to ticagrelor's fast, potent, and uniform pharmacodynamic features $[2,3]$.

Based on the mentioned results, therapy with ticagrelor received class I B recommendation according to the European Society of Cardiology (ESC) in interventionally treated STEMI patients and in all moderate-to-high risk patients with ACS without persistent ST-segment elevation, including NSTEMI patients, regardless of initial treatment strategy $[4,5]$. Likewise, the American College of Cardiology Foundation and American Heart Association (ACCF/AHA) Task Force on Practice Guidelines recommend the use of ticagrelor in these subsets of patients [6,7].
The same ESC and ACCF/AHA guidelines recommend the use of morphine as a treatment of choice for pain relief in the clinical setting of myocardial infarction [4-6]. However, these recommendations, although strong, are only based on expert consensus. Pain relief in patients presenting with acute myocardial infarction (AMI) is suggested to lead to decreased sympathetic activation, thus preventing vasoconstriction and subsequent increase in the workload of the heart. Additionally, apart from its analgesic effects, morphine also alleviates the work of breathing and reduces anxiety $[4,6]$. On the other hand, despite its favorable analgesic and sedative actions, morphine also exerts adverse effects, which include hypotension, bradycardia, respiratory depression, vomiting, and reduction of gastrointestinal motility. Importantly, both the safety and efficacy of morphine have never been tested in randomized trials in the ACS setting, while a large, retrospective analysis of the CRUSADE registry suggests that morphine administration may be associated with increased mortality in patients with non-ST-segment elevation ACS [8]. Some of the previously listed side effects of morphine could affect the intestinal absorption and thus the pharmacokinetics (PK) and pharmacodynamics (PD) of orally administered drugs which are concomitantly used with morphine. Note that currently all commercially available P2Y12 blockers are oral agents.

In concordance with those facts, it was observed that morphine lags clopidogrel absorption, decreases plasma levels of clopidogrel and its active metabolite, and delays and diminishes antiplatelet effects of this thienopyridine, although this was observed in a group of healthy volunteers [9]. Moreover, Parodi et al. in their study comparing the PD of ticagrelor and prasugrel in STEMI patients reported that morphine administration may be associated with impaired antiplatelet effects of both investigated drugs [10].

However, a definitive evidence of a possible interaction between morphine and the novel P2Y12 receptor antagonists may be obtained only in randomized studies. At present, no PK and PD data regarding the concurrent use of morphine and P2Y12 blockers in the ACS setting are available. Therefore, evidence-based verification of morphine's influence on the PK and PD of ticagrelor and its active metabolite (AR-C124910XX) could provide a valuable insight into the knowledge regarding modern ACS management.

\section{Methods/design}

\section{Study objectives}

The primary objective of the Influence of Morphine on Pharmacokinetics and Pharmacodynamics of Ticagrelor in Patients with Acute Myocardial Infarction (IMPRESSION) study is to test the hypothesis that intravenous administration of morphine prior to ticagrelor administration in 


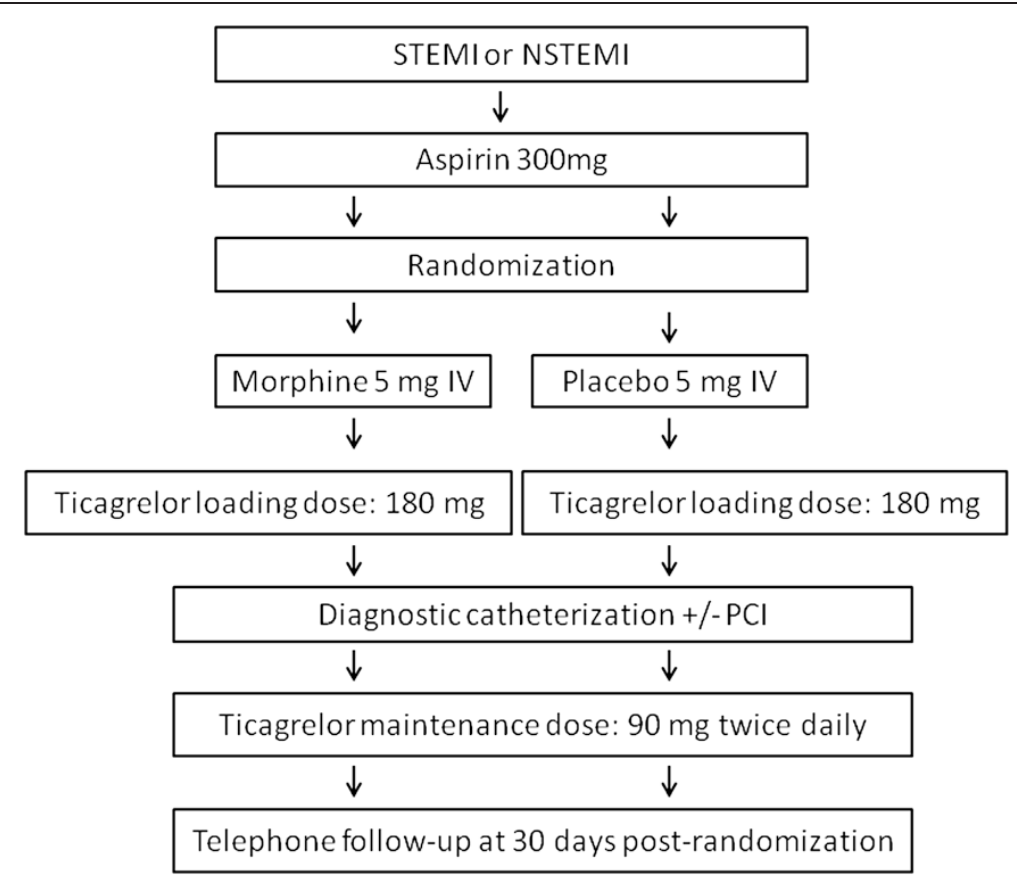

Figure 1 Trial schema for the IMPRESSION study. Legend: IV: intravenous; PCl: percutaneous coronary intervention.

patients with AMI alters the plasma concentrations of ticagrelor and its active metabolite.

The secondary objective of this study is to determine whether intravenous administration of morphine prior to ticagrelor administration in AMI patients attenuates the antiplatelet effects of ticagrelor.

Additionally, a predefined subanalysis has been planned to investigate which of the platelet reactivity assessment methods utilized in the study best reflects concentration of ticagrelor and its active metabolite.

\section{Study design and population}

The IMPRESSION study is a phase IV, single center, randomized, double-blind, placebo-controlled, PK and PD clinical trial. The study population includes subjects presenting with AMI, including both STEMI and NSTEMI patients. After admission to the study center (Cardiology Clinic, Dr. A. Jurasz University Hospital, Bydgoszcz, Poland) and confirmation of the initial STEMI or NSTEMI diagnosis, patients will receive orally a 300-mg loading dose of plain aspirin and will be screened for eligibility for the study. The inclusion and exclusion criteria are as listed in Table 1. Eligible patients will be randomly assigned in a 1:1 ratio to one of two study arms. The patients in the intervention arm will receive $5 \mathrm{mg}$ of morphine intravenously (IV) followed by a 180-mg loading dose of ticagrelor, whereas patients in the control arm will obtain $5 \mathrm{mg}$ of a placebo IV followed by a 180-mg loading dose of ticagrelor (Figure 1). Subsequently all patients will undergo a coronary angiography followed by percutaneous coronary intervention (PCI), if necessary. Blood samples for PK and PD assessment will be drawn at eight predefined time points during the first 12 hours after randomization, according to the blood sampling schedule as presented in Figure 2. A telephone follow-up will be conducted at 30 days post-randomization, which will conclude the subject's participation in the study.

The study will be conducted in accordance with the principles contained in the Declaration of Helsinki, and the study site received approval from the Local Ethics Committee to conduct the study (Komisja Bioetyczna Uniwersytetu Mikołaja Kopernika w Toruniu przy Collegium Medicum im. Ludwika Rydygiera w Bydgoszczy; study approval reference number KB 111/2014). Each patient will provide a written informed consent to participate in the study.

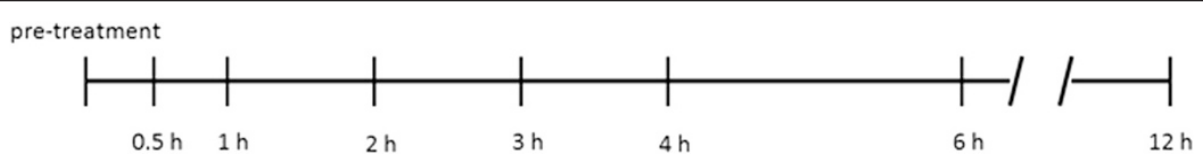

Figure 2 Blood sampling schedule for the IMPRESSION study. 


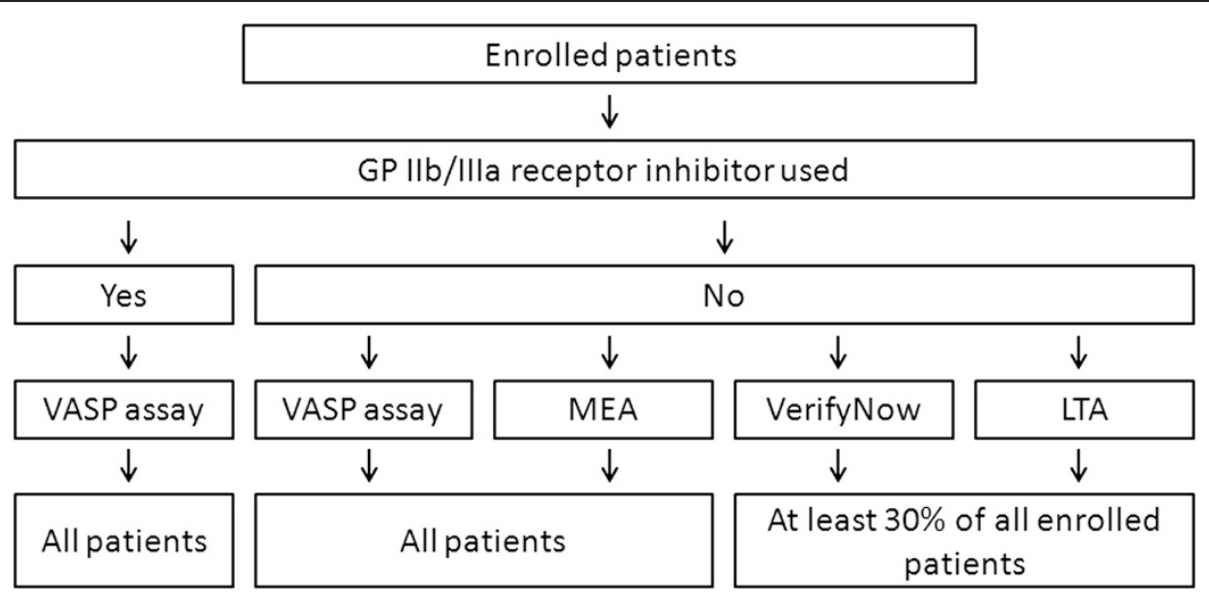

Figure 3 Pharmacodynamic assessment schedule for IMPRESSION study. Legend: GP IIb/IIla: glycoprotein IIb/IIla; LTA: light transmission aggregometry; MEA: multiple electrode aggregometry.

\section{Pharmacokinetics}

Blood plasma concentrations of ticagrelor and ARC124910XX will be evaluated using liquid chromatography mass spectrometry in samples obtained in eight predefined time points (Figure 2).

\section{Pharmacodynamics}

Assessment of ticagrelor's antiplatelet effects will be performed using up to four different methods (Figure 3). A platelet vasodilator-stimulated phosphoprotein (VASP) assay will be applied to all study participants at all predefined time points (Figure 2). Multiple electrode aggregometry (MEA) will be used at all predefined time points for all study participants with the exception of those treated with glycoprotein IIb/IIIa (GP IIb/IIIa) receptor inhibitors. VerifyNow and light transmission aggregometry (LTA) will be applied for at least 30\% of all enrolled study participants at all predefined time

Table 2 Baseline characteristics

\begin{tabular}{llll}
\hline & STEMI (n= 22) & NSTEMI (n= 11) & Total (n= 33) \\
\hline Age in years, median & 62.6 & 62.4 & 62.5 \\
Age $\geq 70$ & $9(40.9 \%)$ & $2(18.2 \%)$ & $9(27.3 \%)$ \\
Female & $5(22.7 \%)$ & $2(18.2 \%)$ & $7(21.2 \%)$ \\
Hypertension & $7(31.8 \%)$ & $8(72.7 \%)$ & $15(45.5 \%)$ \\
Diabetes mellitus & $5(22.7 \%)$ & $2(18.2 \%)$ & $7(21.2 \%)$ \\
Dyslipidemia & $19(86.4 \%)$ & $8(72.7 \%)$ & $27(81.8 \%)$ \\
Current smoker & $9(40.9 \%)$ & $6(54.5 \%)$ & $15(45.5 \%)$ \\
Prior Ml & $1(4.5 \%)$ & $3(27.3 \%)$ & $4(12.2 \%)$ \\
Prior PCl & $1(4.5 \%)$ & $5(45.5 \%)$ & $6(18.2 \%)$ \\
Prior CABG & 0 & 0 & 0 \\
BMl in kg/m ${ }^{2}$ & 28.4 & 27.4 & 28.1 \\
\hline
\end{tabular}

BMI: body mass index; CABG: coronary artery bypass surgery; MI: myocardial infarction. points. Measurements with VerifyNow and LTA will not be performed in patients treated with GP IIb/IIIa receptor inhibitors. Details regarding methods to be used for the assessment of platelet reactivity were previously described [11-14].

\section{Treatment protocol and concomitant medications}

During their participation in the study, all patients will be treated according to the current ESC guidelines. Administration of GP IIb/IIIa receptor inhibitors will be restricted to bailout situations. Interventional cardiologists will be encouraged to use manual thrombectomy in case of visible thrombus. The choice of the access of the coronary invasive procedure (radial or femoral) and the type of implanted stent (drug-eluting stent [DES] or bare metal stent [BMS]) will be at the discretion of the operator, although high rates of radial access and DES implantation are expected to occur. From the loading dose of ticagrelor until completion of the study, all patients will receive maintenance doses of ticagrelor $(90 \mathrm{mg}$ ) twice daily. In addition, standard therapy will include aspirin (75 to $100 \mathrm{mg}$ daily), beta blockers, statins, and angiotensin-converting enzyme inhibitors or angiotensin II receptor blockers, if not contraindicated.

\section{Study endpoints}

The primary endpoint of this trial is the area under the plasma concentration-time curve $\left(\mathrm{AUC}_{(0-12)}\right)$ for ticagrelor for the first 12 hours after the loading dose of ticagrelor. Secondary endpoints include $\mathrm{AUC}_{(0-12)}$ for AR-C124910XX, maximum concentration ( $\mathrm{Cmax}$ ) of ticagrelor and AR-C1 24910XX, time to Cmax for ticagrelor and AR-C124910XX, platelet reactivity index (PRI) assessed by VASP assay, area under the aggregation curve assessed by MEA, P2Y12 reaction units (PRU) assessed by VerifyNow, and ADPinduced platelet aggregation assessed by LTA. 


\section{Safety}

The following safety endpoints will be recorded: definite stent thrombosis according to the Academic Research Consortium criteria, major and minor, recurrent myocardial infarction according to the Third Universal Definition of Myocardial Infarction, all-cause death, stroke, and transient ischemic attack (TIA) according to definitions used in the PLATO trial, minor and major bleedings according to the BARC, PLATO, and TIMI criteria, dyspnea adverse events according to criteria used in the PLATO trial, bradyarrhythmic events according to criteria used in the PLATO trial.

\section{Statistics}

Since there is no reference study examining the PK of ticagrelor in patients presenting with STEMI or NSTEMI, we decided to perform an internal pilot study of approximately 30 patients (15 patients for each arm) to estimate the final sample size. The means and standard deviations of $\mathrm{AUC}_{(0-12)}$ for ticagrelor in the first 33 patients assessed for patients who received morphine and for patients who received the placebo were 6,917 \pm 4,920 and 10,379 $\pm 5,996 \mathrm{ng} \cdot \mathrm{h} / \mathrm{ml}$, respectively. Based on these results and assuming a two-sided alpha value of 0.05 , we calculated, using the $t$-test for independent variables, that enrollment of 68 patients would provide an $80 \%$ power to demonstrate a significant difference in $\mathrm{AUC}_{(0-12)}$ for ticagrelor between patients who received morphine prior to a loading dose of ticagrelor and those who received the placebo prior to the ticagrelor loading dose.

Continuous variables will be compared between both study arms by the Student's $t$-test or the Mann-Whitney $U$ test, depending on the presence or absence of the normal distribution (as assessed by the Kolmogorov-Smirnov test). Proportions will be compared by the Fisher exact test or chi-square test when appropriate. Pharmacokinetic calculations will be performed using a dedicated software.

\section{Discussion}

The IMPRESSION study is a phase IV, single center, randomized, double-blind, placebo-controlled clinical trial that assesses the influence of morphine on the PK and antiplatelet effects of ticagrelor in patients with myocardial infarction. This trial will provide important information regarding the impact of morphine, the analgesic which is most commonly used in patients with AMI, on the absorption of ticagrelor in subjects presenting with STEMI and NSTEMI. Furthermore, the study could specify the suspected connection between alterations in ticagrelor absorption and modification of its antiplatelet activity. A disclosure of such drug-drug interaction in AMI patients could supply a significant evidence-based data source regarding concurrent use of ticagrelor and morphine in STEMI and NSTEMI treatment.

\section{Trial status}

The first patient was enrolled in August 2014. Initially the IMPRESSION study was planned to include STEMI patients only. However, on 9 September 2014, after the approval of the Local Ethics Committee, the trial population was expanded to include subjects with NSTEMI as well. By 8 January 2015, 33\% of planned patients were successfully included in the study. The baseline characteristics of the enrolled patients are presented in Table 2.

\section{Abbreviations}

ACCF/AHA: American College of Cardiology Foundation and American Heart Association; ACS: acute coronary syndromes; AMI: acute myocardial infarction; AUC: area under the curve; BMS: bare metal stent; Cmax: maximum concentration; DES: drug-eluting stent; ESC: European Society of Cardiology; GP IIb/Illa: glycoprotein IIb/Illa; IV: intravenously; LTA: light transmission aggregometry; MEA: multiple electrode aggregometry; NSTEMI: non-ST-segment elevation myocardial infarction; PCl: percutaneous coronary intervention; PD: pharmacodynamics; PK: pharmacokinetics; PRI: platelet reactivity index; PRU: P2Y12 reaction units; STEMI: ST-segment elevation myocardial infarction..

\section{Competing interests}

Dr. Marek Koziński and Dr. Grzegorz Grześk received honoraria for lectures from AstraZeneca. The authors declare that they no competing interests.

\section{Authors' contributions}

JK conceived the study, participated in its design and its further development, and drafted the manuscript. PA participated in the design of this study and its further development and drafted the manuscript. MO, MK, $\mathrm{KO}, \mathrm{EL}$, and $\mathrm{EO}$ participated in the design of this study and its further development. GG, PW, and PP participated in the development of the study protocol. All authors read and approved the final version of the manuscript.

\section{Acknowledgements}

We would like to thank all participating cardiology specialists and residents working in the Cardiology Clinic at Dr. A. Jurasz University Hospital, Bydgoszcz, Poland, who contributed their input by performing the initial screening of admitted patients. We also would like to thank the nursing staff working in the Intensive Cardiology Care Unit and in the Catheterization Laboratory, Cardiology Clinic at Dr. A. Jurasz University Hospital, Bydgoszcz, Poland for their assistance in the blood sample drawing. Moreover, we gratefully acknowledge Joanna Sikora for her input in the organizational and technical preparation of the study.

\section{Funding}

The study is funded by Collegium Medicum of Nicolaus Copernicus University and did not receive any external funding.

\section{Author details}

'Department of Cardiology and Internal Medicine, Nicolaus Copernicus University, Collegium Medicum, 9 Skłodowskiej-Curie Street, 85-094 Bydgoszcz, Poland. ${ }^{2}$ Department of Principles of Clinical Medicine, Nicolaus Copernicus University, Collegium Medicum, 9 Skłodowskiej-Curie Street, 85-094 Bydgoszcz, Poland. ²Department of Pharmacology and Therapy, Nicolaus Copernicus University, Collegium Medicum, 9 Skłodowskiej-Curie Street, 85-094 Bydgoszcz, Poland. ${ }^{4}$ Dr. J. Biziel Memorial University Hospital No. 2, 75 Ujejskiego Street, 85-168 Bydgoszcz, Poland.

Received: 27 January 2015 Accepted: 15 April 2015

Published online: 29 April 2015

\section{References}

1. Wallentin L, Becker RC, Budaj A, Cannon CP, Emanuelsson H, Held C, et al. Ticagrelor versus clopidogrel in patients with acute coronary syndromes. N Engl J Med. 2009;361:1045-57.

2. Navarese EP, Buffon A, Kozinski M, Rychter M, Obonska K, Kunadian V, et al. A critical overview on ticagrelor in acute coronary syndromes. QJM. 2013;106:105-15 
3. Navarese EP, Verdoia M, Schaffer A, Suriano P, Kozinski M, Castriota F, et al. Ischaemic and bleeding complications with new, compared to standard, ADP-antagonist regimens in acute coronary syndromes: a meta-analysis of randomized trials. QJM. 2011;104:561-9.

4. Task Force on the management of ST-segment elevation acute myocardial infarction of the European Society of Cardiology (ESC), Steg PG, James SK, Atar D, Badano LP, Blömstrom-Lundqvist C, et al. ESC Guidelines for the management of acute myocardial infarction in patients presenting with ST-segment elevation. Eur Heart J. 2012;33:2569-619.

5. Hamm CW, Bassand JP, Agewall S, Bax J, Boersma E, Bueno H, et al. ESC Guidelines for the management of acute coronary syndromes in patients presenting without persistent ST-segment elevation: The Task Force for the management of acute coronary syndromes (ACS) in patients presenting without persistent ST-segment elevation of the European Society of Cardiology (ESC). Eur Heart J. 2011;32:2999-3054.

6. O'Gara PT, Kushner FG, Ascheim DD, Casey Jr DE, Chung MK, De Lemos J, et al. 2013 ACCF/AHA guideline for the management of ST-elevation myocardial infarction: executive summary: a report of the American College of Cardiology Foundation/American Heart Association Task Force on Practice Guidelines. Catheter Cardiovasc Interv. 2013;82:E1-27.

7. Jneid H, Anderson JL, Wright RS, Adams CD, Bridges CR, Casey Jr DE, et al. 2012 ACCF/AHA focused update of the guideline for the management of patients with unstable angina/Non-ST-elevation myocardial infarction (updating the 2007 guideline and replacing the 2011 focused update): a report of the American College of Cardiology Foundation/American Heart Association Task Force on Practice Guidelines. J Am Coll Cardiol. 2012;60:645-81.

8. Meine TJ, Roe MT, Chen AY, Patel MR, Washam JB, Ohman EM, et al. Association of intravenous morphine use and outcomes in acute coronary syndromes: results from the CRUSADE Quality Improvement Initiative. Am Heart J. 2005;149:1043-9.

9. Hobl EL, Stimpfl T, Ebner J, Schoergenhofer C, Derhaschnig U, Sunder-Plassmann $\mathrm{R}$, et al. Morphine decreases clopidogrel concentrations and effects: a randomized, double blind, placebo-controlled trial. J Am Coll Cardiol. 2014;63:630-5.

10. Parodi G, Valenti R, Bellandi B, Migliorini A, Marcucci R, Comito V, et al. Comparison of prasugrel and ticagrelor loading doses in ST-segment elevation myocardial infarction patients: RAPID (Rapid Activity of Platelet Inhibitor Drugs) primary PCl study. J Am Coll Cardiol. 2013;61:1601-6.

11. Kubica A, Kasprzak M, Siller-Matula J, Koziński M, Pio Navarese E, Obońska K, et al. Time-related changes in determinants of antiplatelet effect of clopidogrel in patients after myocardial infarction. Eur J Pharmacol. 2014;742:47-54.

12. Koziński M, Obońska K, Stankowska K, Navarese EP, Fabiszak T, Stolarek W, et al. Prasugrel overcomes high on-clopidogrel platelet reactivity in the acute phase of acute coronary syndrome and maintains its antiplatelet potency at 30-day follow-up. Cardiol J. 2014:21:547-56.

13. Kozinski M, Bielis L, Wisniewska-Szmyt J, Boinska J, Stolarek W, Marciniak A, et al. Diurnal variation in the platelet inhibition by clopidogrel. Platelets. 2011;22:579-87.

14. Tantry US, Bonello L, Aradi D, Price MJ, Jeong YH, Angiolillo DJ, et al. Consensus and update on the definition of on-treatment platelet reactivity to adenosine diphosphate associated with ischemia and bleeding. J Am Coll Cardiol. 2013;62:2261-73

\section{Submit your next manuscript to BioMed Central and take full advantage of:}

- Convenient online submission

- Thorough peer review

- No space constraints or color figure charges

- Immediate publication on acceptance

- Inclusion in PubMed, CAS, Scopus and Google Scholar

- Research which is freely available for redistribution

Submit your manuscript at www.biomedcentral.com/submit 